\title{
Photodynamic Therapy for the Treatment of Oral HPV Lesion in a Patient with Oral Lichen Planus. A Case Report
}

\author{
Cinzia Casu* \\ Private Dental Practice, Italy \\ *Corresponding author: Cinzia Casu, President of AIRO, Private Dental Practice, Cagliari, Italy \\ To Cite This Article: Cinzia Casu. Photodynamic Therapy for the Treatment of Oral HPV Lesion in a Patient with Oral Lichen Planus. A Case \\ Report. Am J Biomed Sci \& Res. 2019 - 1(5). AJBSR.MS.ID.000550. DOI: 10.34297/AJBSR.2019.01.000550
}

Received: January 06, 2019 | Published: March 11, 2019

\begin{abstract}
Human papilloma viruses (HPVs) are a group of double-stranded DNA, that cause different type of lesions, also on oral cavity. Lichen planus (LP) is a chronic inflammatory mucocutaneous disease affecting the oral cavity and skin. Photodynamic therapy (PDT) is a treatment used in all fields of medicine, based on the interaction between a photosensitizer, the appropriate wavelength, and oxygen. The reaction generates ROS in cells that take up the photosensitizer, causing cell death by necrosis or apoptosis. Different parameters are described in the literature for PDT. We would like to report a case of a patient with diagnosis of Oral lichen planus that developed, and HPV lesion treated with a particular type of PDT. I have not found other cases of Photodynamic Therapy for the treatment of oral HPV lesions, in the scientific literature.
\end{abstract}

Keywords: HPV lesion; Oral lichen planus; Photodynamic Therapy; Toluidine Blu; Diode light

\section{Introduction}

Human papilloma viruses (HPVs) are a group of double-stranded DNA [1]. Human Papillomavirus (HPV) infection is considered the most common sexually transmitted infection. About 6 million people are diagnosed each year and approximately $9.0-13.0 \%$ of the world population is already infected with the disease [2]. There are a lot of subtypes of HPV (more than 120), and some of these HPV plays a role in the pathogenesis of Head and Neck Squamous Cell Carcinomas and Oropharyngeal Squamous Cell Carcinoma [2,3]. Different types of HPV lesions could occur in oral cavity. Oral squamous papilloma is benign exophytic lesions presenting as papillary or verruciform proliferation. That is softened/flaccid in $66.7 \%$ of cases and pedunculated in $75 \%$ of the lesions. The most commonly associated with HPV 6, 11, and 16 [4]. Verruca vulgaris is a benign epidermal proliferation that affect overall the skin and sometimes the oral mucosa and the clinical presentations vary according to the viral type and the anatomical site infected. Verruca vulgaris is most commonly induced by HPV-2, HPV-4 or HPV40 and it rarely occurs on the tongue [5]. Condyloma acuminate appear most frequently as soft, pink cauliflower like growths in moist areas, such as the genitalia, mouth and other places [6]. Focal epithelial hyperplasia (FEH), or Heck's disease, is a rare disease of the oral mucosa, with multiple soft lesions associated with infection of subtypes 13 or 32 [7].

Lichen planus (LP) is a chronic inflammatory mucocutaneous disease affecting the skin, mucous membranes or both. It is recurrent and of unknown etiology. The typical clinical findings related to oral lichen planus (OLP), especially the presence of a reticular, bilateral and symmetrical pattern, are normally deemed sufficient for the clinical diagnosis of the disease, but a biopsy is recommended to confirm clinical diagnosis [8]. Various topically treatments are described for the OLP including: Corticosteroids, immunosuppressants such as cyclosporin, tacrolimus, and retinoids. The most commonly used drugs are Corticosteroids, but also azathioprine, calcineurin inhibitors, mycophenolate mofetil, dapsone, retinoids, and hydroxychloroquine can be used in recalcitrant cases [9].

Photodynamic therapy (PDT) is a particular type of treatment used in all fields of medicine, based on the interaction between a photosensitizer, the appropriate wavelength, and oxygen. The reaction generates ROS in cells that take up the photosensitizer, 
causing cell death by necrosis or apoptosis [10]. Different types of photosensitizer are used such as Methylen Blue, Toluidine Blue, Indocianine green and so on, to perform PDT. Different types of lights are described in the literature, lasers or LEDs, and there are a lot of different parameters for each type of disease or lesions [10]. I would like to describe a case of HPV lesion, in a patient with OLP, treated with a single session of PDT.

\section{Case Presentation}

A 58 years old female patient, with a previous diagnosis of oral lichen planus went to my private practice for a follow up visit. The medical anamnesis was positive for hysterectomy about 30 years ago, arthrosis, mild hypertension, gastro-esophageal reflux. A new asymptomatic lesion between the gingival papilla of the element 24 and 25 was present. It is an exophytic pink-white lesion, of irregular shape, of about $0,5 \mathrm{~cm}$, near gingival lesion already present due to the oral lichen planus. The patient did not want to perform a histological examination in that day because she had an important event the day after. I have decided to treat the region between the gum around the element 24 and 25 with a session of photodynamic therapy (PDT). PDT was performed with a $630 \mathrm{~nm}$ LED red light (FotoSan 630, CMD Dental, Cophenagen, Denmark) in combination with Toluidine Blue $(0,1 \mathrm{mg} / \mathrm{ml})$. The lights applied have very mild affinity with mammalian cells.

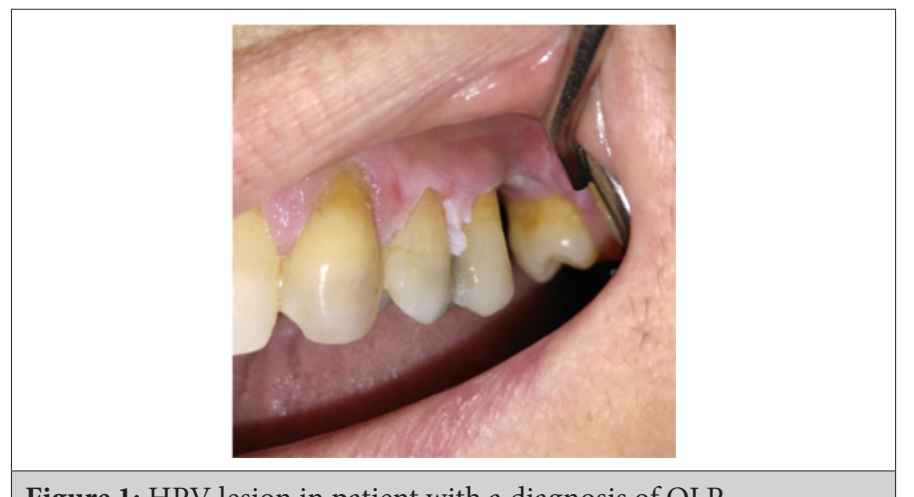

Figure 1: HPV lesion in patient with a diagnosis of OLP.

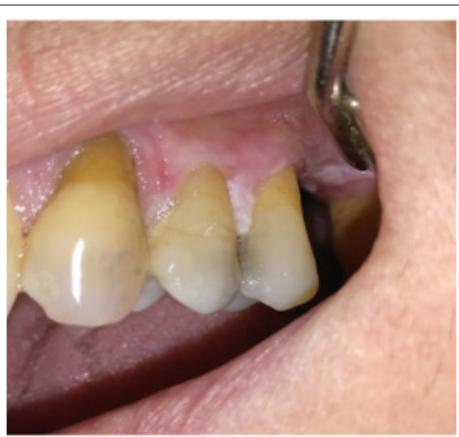

Figure 2: Reduced HPV lesion after PDT.

For this there are no adverse effects during the treatments. The intensity of the light that emitted diodes is between 2000 and $4000 \mathrm{MW} / \mathrm{cm}^{2}$. This device works with three different modalities that correspond to different time cycles of application: 10,20, and 30 seconds, respectively. The dye was applied on the entire surface of the lesion beyond the margins and even encroaching on healthy tissue. The light diode was then turned on with a wavelength of $630 \mathrm{~nm}$ with 5 cycles of 30 seconds. a long-pipped tip was used and circular movements of about $0.5 \mathrm{~cm}$ above it were performed. At the end of the 5 applications, the dye was completely removed with a gauze and the patient performed a final rinsing with water. One week later, the exophytic lesion was reduced, of about $0,3 \mathrm{~mm}$ and hade a regular shape. The gingival tissue around the element 24 returned pink (Figures $1 \& 2$ ). I have decided to remove the exophytic lesion with a biopsy for an histological examination, that confirmed the diagnosis of squamous papilloma from HPV infection. After one week, at the follow up visit the tissues healed (Figure 3). I have informed the patient about the risk connected with the development of oral cancer in patient with oral lichen planus and HPV lesions.

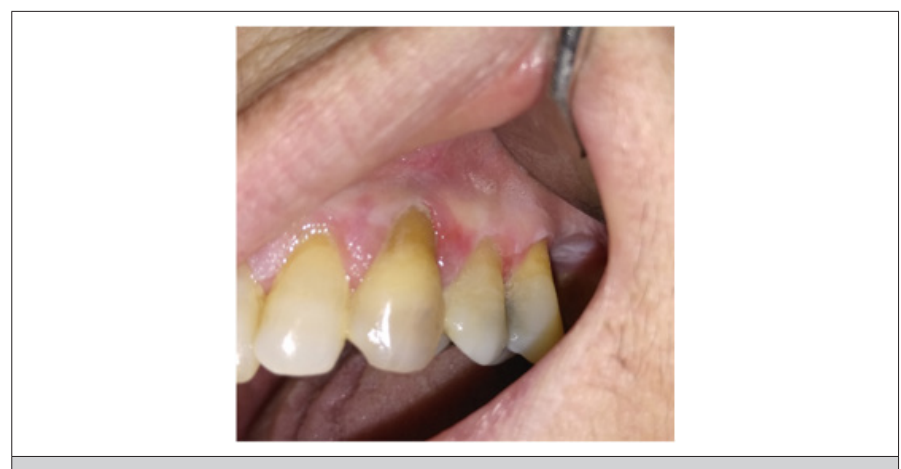

Figure 3: Healing of the lesion.

\section{Discussion}

For the treatment of oral HPV the gold standard is considered surgical excision with different instruments. The use of Imiquimod has been documented in the literature, especially for small lesions [11]. Researchers also experimented the use of lasers, but I found no work on using PDT for HPV lesions [12,13]. Different types of photodynamic therapy have been used for the treatment of OLP, with very variable parameters. The alpha aminolaevulinic acid, methylene blue, toluidine blue are the most documented photosensitizers $[14,15]$. In some studies, it was seen that PDT for the treatment of OLP gave the same or better results to conventional therapy with corticosteroids or immunosuppressants [16]. The same device that was used in this work was tested for PDT on OLP erosive lesions, with excellent results [17]. Photodynamic therapy has also been used successfully for the treatment of other viral infections of the oral cavity, such as for herpes simplex virus [18,19]. Photodynamic therapy sessions could be a valid alternative to surgical excision in the treatment of squamous papilloma and could also be proposed to reduce the viral load of HPV, thus reducing the risk of possible malignant transformation. Further clinical studies must be performed to establish the most appropriate protocol, with the most effective parameters.

\section{References}

1. Mattoscio D, Medda A, Chiocca S (2018) Human Papilloma Virus and Autophagy. Int J Mol Sci 19(6): 1775.

2. Candotto V, Lauritano D, Nardone M, Baggi L, arcuri C, et al. (2017) HPV infections in the oral cavity: epidemiology, clinical manifestations and relationship with oral cancer. Oral Implantology 10(3): 209-220. 
3. Shah A, Malik A, Garg A, Mair M, Sudhir Nair, et al. (2017) Oral sex and human papilloma virus-related head and neck squamous cell cancer: a review of the literature. Postgrad Med J 93(1105): 704-709.

4. Chaitanya P, Martha S, Punithvathy R, Reddy M (2018) Squamous Papilloma on Hard Palate: Case Report and Literature Review. Int J Clin Pediatr Dent 11(3): 244-246.

5. Ural A, Arslan S, Ers.z S, Değer B (2014) Verruca vulgaris of the tongue: a case report with literature review. Bosn J Basic Med Sci;14(3): 136-138.

6. Percinoto ACC, Danelon M, Crivelini MM, Cunha RF, Percinotto C (2014) Condyloma acuminata in the tongue and palate of a sexually abused child: a case report. BMC Research Notes 7: 467.

7. de Castroa LA, de Castroa JGL, da Cruza ADL, de Sousa Barbosaa BH, de Spindula-Filhob JV, et al. (2016) Focal Epithelial Hyperplasia (Heck's Disease) in a 57-Year-Old Brazilian Patient: A Case Report and Literature Review. J Clin Med Res 8(4): 346-350.

8. Cassol-Spanemberg J, Rodríguez-de Rivera-Campillo ME, Otero-Rey EM, Estrugo-Devesa A, Jané-Salas E, et al. (2018) Oral lichen planus and its relationship with systemic diseases. A review of evidence. J Clin Exp Dent 10(9): e938-e944.

9. Nosratzehi T (2018) Oral Lichen Planus: An Overview of Potential Risk Factors, Biomarkers and Treatments. Asian Pac J Cancer Prev 19 (5): 1161-1167.

10. Ali M Rkein, David M Ozog (2014) Photodynamic Therapy. Dermatol Clin 32: 415-425.

11. Esquivel-PedrazaL, Fernandez-Cuevas L, Saeb-Lima M, Guerrero-Ramos BA, Silvia M.ndez-Flores, et al. (2015) Recalcitrant oral squamous cell papilloma lesions in two HIV infected patients successfully treated with topical imiquimod. J Dermatol Case Rep 9(1): 19-22.

12. Boj J, Hernandez M, Espasa E, Espanya A. (2014) Oral focal fibrous hyperplasia and squamous cell papilloma treated with an erbium laser Case presentation. Refuat Hapeh Vehashinayim (1993) 31(1): 9-14, 59.

13. Akyol A, Anadolu R, Anadolu Y, Ekmekci P, Gürgey E, et al. (2003) Multifocal papillomavirus epithelial hyperplasia: successful treatment with CO2 laser therapy combined with interferon alpha-2b. Int J Dermatol 42(9): 733-735.

14. Sulewska M, Duraj E, Sobaniec S, Graczyk A, Milewski R, et al. (2017) A clinical evaluation of the efficacy of photodynamic therapy in the treatment of erosive oral lichen planus: A case series. Photodiagnosis Photodyn Ther 18: 12-19.

15. Jajarm HH, Falaki F, Sanatkhani M, Ahmadzadeh A, Ahrari A, Shafaee H (2015) A comparative study of toluidine blue-mediated photodynamic therapy versus topical corticosteroids in the treatment of erosiveatrophic oral lichen planus: a randomized clinical controlled trial. Lasers Med Sci. 30(5): 1475-1480.

16. Al-Maweri SA, Ashraf S, Kalakonda B, Halboub E, Petro W, etal. (2018) Efficacy of photodynamic therapy in the treatment of symptomatic oral lichen planus: a systematic review. J Oral Pathol Med 47(4): 326-332.

17. Bakhtiari S, Azari-Marhabi S, Mojahedi SM, Namdari N, Rankohi ZE, et al. (2017) Comparing clinical effects of photodynamic therapy as a novel method with topical corticosteroid for treatment of Oral Lichen Planus. Photodiagnosis And Photodynamic Therapy S1572- 1000(16): 30110 30117.

18. Marotti J, Sperandio FF, Fregnani ER, Correa Aranha AC, de Freitas PM, et al. (2010) High-Intensity Laser and Photodynamic Therapynas a Treatment for Recurrent Herpes Labialis. Photomedicine and Laser Surgery 28(3): 439-444.

19. Jalilian FA. (2018) Effect of photodynamic therapy by 810 and $940 \mathrm{~nm}$ diode laser on Herpes Simplex Virus 1: An in vitro study. Photodiagnosis Photodynamic Ther. S1572-1000(18): 30264-30273. 